трудность[2]. Актуальными при определении трудности текста являются фоновые знания читателя, зависимые от социальных, исторических, психологических, научнотеоретических, общекультурных, возрастных, временных и прочих факторов, поскольку коммуникация признается успешной при наличии у адресата (читателя в данном случае) «трех типов компетенций: когнитивной, предметной и языковой, в которых закреплен концептуальный, перцептивный и вербальный опыт личности, полученный в процессе социализации» [6].

Резюмируя вышеизложенное,уровень сложностиучебного текста играет важную роль при его создании, т.к. корректный подбор качественных и количественных характеристик способствует улучшению усвоения материала, и, как следствие, повышению качества обучения и совершенствованию профессиональной подготовленности специалиста.

$$
* * *
$$

1. Байбалова А.Э. Текст как продукт, средство и объект коммуникации при обучении неродному языку. Саратов: изд-во Саратовского университета, 1987. - 152 с.

2. Кисельников А.С. Экзаменационный текст: сущность, специфика, функции (на материале русского и английского языков) [Текст]: дисс. ... канд. филол. наук: 10.02.20 / Кисельников Александр Сергеевич - Казань, 2016. - 243

3. Сабинина, А. А. Учебный текст: структура и прагматика [Текст] / А. А. Сабинина // Известия РГПУ им. А. И. Герцена. - Санкт-Петербург: Российский государственный педагогический университет им. А.И. Герцена, 2009. - № 97. - С. 222-225.

4. Семерджиди В.Н. Лингвистические и дидактические особенности учебного текста на иностранном языке (русском и английском) [Электронный ресурс] / В.Н. Семерджиди // Вестник ВГУ, серия: Лингвистика и межкультурная коммуникация, 2007. №2, Ч. 1. - С. 117-122. . Режим доступа: https://cyberleninka.ru/article/v/lingvisticheskie-i-didakticheskie-osobennosti-uchebnogo-teksta-nainostrannom-yazyke-russkom-i-angliyskom.html (дата обращения: 20.08.2017).

5. Солнышкина М.И., Кисельников А.С. Параметры сложности экзаменационных текстов [Текст] / М. И. Солнышкина, А.С. Кисельников // Вестник Волгоградского гос. ун-та. - 2015. - Серия 2. Языкознание. №1 (25) - С. 99-106.

6. Солнышкина, М. И. Эклектика институционального дискурса: норма или нарушение? [Текст] / М. И. Солнышкина, М. Б. Казачкова, Т. Е. Калинкина // Филологические науки. Вопросы теории и практики. - Тамбов: Грамота, 2015. - № 12(54): в 4-х ч. Ч. І. С. 164-168.

7. Яхиббаева Л.М. Учебный текст как особый вид вторичного текста и составляющая учебного дискурса. // Вестник Башкирского университета, 2008. Т. 13, №4 - С. 1029 - 1031.

\title{
Петрова Е.E. \\ Модные слова английского языка в сфере повседневной жизни
}

Санкт-Петербургский государственньй университет (Россия, Санкт-Петербург)

doi: $10.18411 / s p c-26-10-2017-05$

idsp: 000001:spc-26-10-2017-05

\section{Abstract}

This article studies some recent English buzzwords in the sphere of everyday life. These words are analyzed in terms of their origin, register, word-formation pattern and use, the examples from modern sources being supplied.

Keywords: buzzword, catch phrase, blend, neologism, abbreviation, loanword, occasional word.

Под модными словами (buzz words, vogue words, fashion words) понимают особый род слов и словосочетаний, которые широко используются в СМИ и в обществе в целом для придания чему-либо образа важности, уникальности или новизны [7]. Их отличительные признаки - современность, актуальность, новизна, частотность, а также довольно короткий жизненный цикл, а также семантическая и прагматическая амбивалентность, которая является следствием расширения синтагматических связей 
[1, с.14; 2, с.45; 4]. Изучение модных слов на стыке таких наук, как социо- и психолингвистика, семиотика, когнитивная лингвистика, лексикология и лингвокультурология представляется актуальным и перспективным.

Целью данной статьи является анализ некоторых модных слов в сфере повседневной жизни последних лет, зарегистрированных словарём "Macmillan Dictionary. Buzzword”, с точки зрения их происхождения, образования и перевода. Сфера повседневной жизни, куда относятся названия самых разных предметов и явлений, мероприятий и развлечений, сильно подвержена моде и соответственно языковой моде. Лексикон справедливо называют «хроникой общества» [Молдованова Л.И., 2008 : 81], поэтому «модные слова» в каждый период времени могут быть признаны самой информативной в социолингвистическом плане категорией лексики.

Noughties /the noughties/ the Noughties: «нулевые» годы, первое десятилетие XXI века. Данное слово образовано аффиксацией от существительного nought (ноль, ничто) - по той же модели, по которой образованы существительные eighties, thirties, fifties u m.d., обозначающие десятилетия. В начале $\mathrm{XX}$ века предлагалось много вариантов обозначения первых годов второго тысячелетия: The Aughts (широко использовалось между 1900 и 1909), the Ohs, the Oh-Ohs, the Zeros, the Two-thousands, the Ones, the Nulls, the Naughties. Вероятно, успех термина the noughties объясняется фонетическим совпадением со словом naughty (озорной, непослушный), что создаёт потенцииал для игры слов - naughty noughties (озорные нулевые) [2].

Humblebrag / humble brag / humble-brag - a statement in which you pretend to be modest but which you are really using as a way of telling people about your success or achievements [2]: «скромное хвастовство». Неологизм humblebrag заполнил лексическую лакуну в языке: это утверждение, сделанное в устной или письменной форме, в котором человек хвастается чем-либо в то же время с оттенком самоуничижения. Существительное humblebrag образовано сложением прилагательного humble (скромный) u глагола brag (хвастаться). Эти слова обозначают противоположные понятия, поэтому лингвистически humblebrag можно считать оксюмороном. Слово humblebrag было создано в 2011 году американским комиком Хэррисом Уиттелсом (Harris Wittels), который создал специальную страницу таких высказываний в Твиттере. Американской диалектологическое общество признало это слово самым полезным словом 2011 года.

Omnishambles - something that is very badly organised and is ineffective in every possible way [2]. Данное слово образовано словосложением от существительного shambles (кавардак) $u$ omni- первый компонент сложных слов, указывающий на всеобщность. Придуманный в 2009 году писателями-сатириками, он означает «беспорядок во всем, полная разруха». Это слово прозвучало в речи лидера британской лейбористской партии Эда Милибэнда (Ed Miliband) в 2012 году в отношении к ситуации провала на всех уровнях. Затем оно было подхвачен СМИ и стало употребляться в более расширенном значении - для описания любой неэффективной деятельности.

Optics - the way a situation looks to the general public [2]: то, как ситуация воспринимается общественностью. Прямое значение существительного optics - оптика, оптические приборы. В переносном, метафорическом значении выражение 'the optics of a situation' обозначает то, как ситуация воспринимается общественностью, каким видится то или иное событие. Чаще всего это значение реализуется в политических контекстах. Слово орtics становится популярным эвфемизмом, обозначающим то впечатление, которое производит на людей то или иное решение или ход событий. По сути это означает, что человек или общественная организация беспокоится об общественном восприятии какого-либо решения больше, нежели о сути этого решения.

Black swan / Black Swan - an event which is extremely rare and unexpected but has very significant consequences [2]: событие типа «чёрный лебедь», редкое и неожиданное 
событие, имеющее важные последствия. Эта субстантивная идиома употребляется и как исчисляемое существительное, и как прилагательное, обычно в выражении blackswan event, чаще всего в финансовом контексте, особенно по отношению $\kappa$ глобальному экономическому кризису последних лет.

Hedonic treadmill / hedonistic treadmill - the tendency to always go back to the same level of happiness despite positive life events [2]: «гедонистическое колесо», тенденция возвращаться на тот же уровень счастья несмотря на большие позитивные изменения события в жизни. Фразема hedonic treadmill основана на метафорическом переосмыслении значения второго компонента - повторяющаяся ситуация, не приводящая к изменениям в лучшую сторону. Данное выражение было создано в 1971 году психологами П.Брикмэном и Д.Кэмпбеллом (P. Brickman and D. Campbell), данная концепция также известна как hedonistic treadmill или hedonic adaptation (гедонистическая адаптаџия). Прилагательные hedonic/hedonistic (гедонический, гедонистический, любящий наслаждения) обозначает постоянное стремление человека к удовольствию и часто ассочиируется с временными источниками счастья, такими как новые покупки, которые поначалу дают ощущение благополучия, но со временем перестают радовать и воспринимаются как норма. Существительное treadmill появилось ещё в начале XIX века в значении «мельница или другая машина, приводимая в действие шагающими людьми или животными», в современном языке означает «беговая дорожка».

Fomo /FOMO - «фомо», страх пропустить важное социальное мероприятие. Это новый модный акроним выражения fear of missing out - постоянная боязнь пропустить что-то очень интересное и важное, что происходит прямо сейчас. Появление и распространение термина FOMO - заслуга социальных сетей. Боязнь пропустить важное событие, желание 24 часа в сутки быть в курсе того, что делают знакомые, приводят к проблемам в социальной жизни, а то и к психическим расстройствам. FOMO касается не только развлекательных мероприятий, но также работы, а в остальных случаях и просто важных новостей и событий, происходящих в мире. FOMO - показательный пример того, как электронная коммуникация, особенно общение в интернете породило множество акронимов и инициальных аббревиатур.

Normcore - a fashion trend in which people intentionally wear ordinary, inexpensive, widely-available clothing [2,6]: «нормкор», современная тенденция в моде обоих полов, характеризующаяся выбором непритязательной одежды, стремление выглядеть «обычно», «как все», не выделяться. Normcore - слиток слов normal (нормальный, обычный) и hardcore (в значении «твёрдый, непреклонный». Оно появилось в словаре Urban Dictionary в 2009 году, но стало употребляться после того, как арт-группа KHOLE упомянула его в своем докладе Youth Mode: A Report on Freedom, опубликованном в конце 2013 года. Нормкор характеризуют как реакцию на перенасыщение модой и слишком быстро меняющиеся модные тенденции, своего рода тенденция «анти-моды». Люди, выбирающие этот стиль, носят то, что подворачивается под руку, но что они сознательно выбирают одежду, которая непримечательна футболки, толстовки, водолазки и ветровки, классические джинсы, кеды и т.д., в основном серых, синих и чёрных тонов. Это является полной противоположностью тому, что принято среди модной элиты - яркие цвета, броские логотипы, индивидуальный стиль.

Dench - extremely attractive, fashionable, impressive, etc. [2]: очень привлекательный, модный, впечатляющий. Данный неологизм является ещё одним примером непрерывного стремления носителей английского языка изобретать новые выражения одобрения. Dench - это неологизм, слэнговый синоним cool в значении «крутой, классный, прикольный», часто употребляемый в восклицательных предложения типа He/She/It/That's well Dench! Dench было создано в 2012 году британским рэп-исполнителем Биззлом (Lethal Bizzle). Возможно, этот неологизм 
не вомёл бы в широкое употребление, если бы не совпал с фамилией известной британской актрисы Джуди Денч (Judi Dench). Сама актриса горячо поддержала это слово.

Food rave - a very large party where people eat, sell or share many different types of food, usually held outside or in a large public building [2]: «Гурманская вечеринка».

Обычно такие банкеты проходят на рыбных, мясных или овощных рынках, либо на отдельной площадке. Смысл «фуд рэйва» в следующем: несколько команд собираются в одном помещении, оборудованном под кухню. У каждой имеется одинаковый набор продуктов и ограниченное количество времени. Помогает и подсказывает командам опытный шеф-повар. Одновременно люди веселятся, слушают музыку, знакомятся и общаются. Это может быть и событие меньшего масштаба, проводимое на дому или на улице с друзьями и соседями. Выражение food rave появилось в 2011 году после успеха такого фестиваля, прошедшего в Сан-Франциско. Оно образовано от существительных food (еда) и rave (вечеринка). Рейв - танцевальная музыка, включающая стили acid house, hard core и др.

Marmite - causing a strong feeling of either liking or disliking [2, 6]: вызывающий сильное чувство либо приязни, либо неприязни. Мармайт - это блюдо британской кухни - пряная пищевая паста, изготовленная из концентрированных пивных дрожжей с добавлением витаминов, трав и специй, которая обычно намазывается на хлеб. Её сильный привкус вызывает сильную реакцию - одни его обожают, у других он вызывает отвращение. Именно эта особенность данного блюда породила метафорическое употребление слова marmite в качестве прилагательного. В разговорном британском варианте это слово заполнило лексическую лакуну для обозначения чего-либо, вызывающего у людей либо любовь, либо ненависть, но не оставляющего их равнодушными. Чаще всего это произведения искусства - музыка, архитектура, театр или кино, а также при описании людей, особенно знаменитостей, чьи выступления вызывают сильную позитивную или негативные реакцию. Marmite может сочетаться и с многими другими существительными - как абстрактными, так и конкретными, обозначающими природные явления, акценты, названия книг, автомобили, электронные игры и т.I. однако это слово не сочетается с наименованиями еды. Значение прилагательного marmite ещё не полностью прозрачно, оно часто сопровождается объяснительным комментарием (см. пример выше - you either love it or hate it. Marmite в том же метафорическом значении может быть и существительным: that film was cinematic Marmite.

Мармайт был впервые произведён в Британии в 1902 году. Название продукта произошло от французского слова marmite - котелок, чугунок. Мармайт сразу же вызвал противоречивые реакции потребителей, чем воспользовались маркетинговые компании, приняв рекламный слоган - "love it or hate it", который и породил метафорическое изменение значения данного слова.

Sick - impressive, especially because of being fashionable or attractive [2]: крутой, классный, сногсшибательный. Sick - новый модный синоним таких прилагательных как excellent, awesome и cool. Новое, положительное значение противоположно традиционным значениям данного прилагательного, имеющим негативную коннотацию - больной, болезненный, скучающий, мрачный и т.д. В этом значении sick употребляется в основном в речи молодых людей - неформальном устном или письменном общении, например в интернете. Обычно оно сочетается с существительными, обозначающими одежду, модные предметы и электронные устройства - мобильные телефоны, компьютеры и т.п., а также в спортивных контекстах. В этом значении sick характеризует высокое качество и обычно не употребляется в сравнительной степени и не сочетается с такими наречиями, как very, slightly, extremely u m.n. например, можно сказать a very sick joke (очень мрачная 
шутка), однако нельзя сказать a very sick outfit. Позитивное значение sick впервые появилось в США в начале 1980-х, а в Британии стало употребляться совсем недавно.

Amazeballs - used to say that something is extremely good, impressive, enjoyable, etc $[2,6]$ : нечто впечатляющее и привлекательное.

Wow, you look totally amazeballs in that outfit!

Неологизм amazeballs пополнил внушительный ряд синонимов для выражения восторженного одобрения чего-либо - amazing, fabulous, fantastic, gorgeous, lovely, wonderful, breathtaking, sensational, phenomenal u m.д. Это слово вошло в моду благодаря американскому телеведущему Пересу Хилтону (Perez Hilton), который использовал его в своём блоге в 2009 году. Однако создателем этого слова является другой модный блоггер - Элизабет Спиридакис (Elizabeth Spiridakis) и её коллегами, которые в шутку стали добавлять суффикс -balls к различным прилагательным: starveballs, hungballs, tiballs, exhaustballs = starving, hungry, tired, exhausted. от слов «удивительный» и «шары») Вероятно, внутренняя форма этого слова такова: шарики (или мячики), сделанные из чего-то удивительного. Это слово, зарегистрированное Collins Online Dictionary и Urban Dictionary вызвало бурный протест у целого ряда профессиональных писателей и обычных блоггеров. Это пример того, как некоторые окказионализмы закрепляются в языке несмотря на негативную реакцию и бурные споры. amazeballs было включено в словарь самых раздражающих слов английского языка (the Dictionary of the Most Annoying Words in the English Language), в котором оно определено как "an exclamation inviting someone to hit you." (восклицание, приглашающее собеседника ударить вас).

Man up - to be brave or to take responsibility for the consequences of your actions [2]: мужаться, собраться с духом, взять себя в руки. Этот фразовый глагол в основном используется в императиве, как в примере: Man up and start doing the right thing. Мужайся и начни поступать правильно! В разговорной речи он встречается либо в инструкциях (e.g.: She told him to man up) или оценочных высказываниях (e.g.: Jack really needs to man up and ...), причём может употребляться по отношению обоих полов. Вхождение в моду данного глагола идёт вразрез с тенденцией «гендерной нейтральности», требуемой политкорректностью (chairperson вместо chairman и т.п.), поскольку значение этого глагола связано со стереотипными мужскими качествами смелостью, мужеством.

Chillax - to rest and relax, often by taking time away from work to do things you enjoy [2]: отдыхать, расслабляться, обычно занимаясь чем-либо приятным. Этот неологизм синонимичен таким словам и словосочетаниям как relax, rest, chill (out), take time out, put your feet up u дp. Непереходный глагол chillax - популярный разговорный синоним обозначающий отдых, перерыв в работе, занятие любимыми делами, приносящими удовольствие.

What are you doing tonight? - Nothing special, just going to chillax at home. (Ничего особенного, просто собираюсь расслабиться дома) [2].

Глагол chillax появился в середине 1990-х годов. Слиток глаголов chill и relax, поначалу он употреблялся в основном в речи подростков и молодёжи в побудительных предложениях типа Chillax, nothing's going to go wrong... (Расслабься, всё будет в порядке). Постепенно этот глагол был подхвачен и более старшими поколениями и слегка изменил значение - «отдыхать для удовольствия». T.e. chillax немного отличается от relax и chill (оut), поскольку содержит импликациональную сему «проводить досуг, занимаясь чем-либо приятным».

Таким образом, в статье были рассмотрены всего 15 модных слов из сферы повседневной жизни, но и на их примере можно отметить их характерные черты: это неологизмы, употребляемые в основном в разговорном стиле речи, образованные такими способами как словослияние (chillax), аффиксация (Naughties), сокращение словосочетаний (FOMO), переосмысление значений (sick). Они могут обладать 
высокой деривационной активностью, образуя однокоренные слова посредством аффиксации либо конверсии (humblebrag - to humblebrag, humblebragger). Большинство этих слов и словосочетаний являются авторскими окказионализмами, имеющими короткий жизненный цикл, и не все они войдут в основной словарный фонд английского языка, однако некоторые из них уже зарегистрированы различными словарями. При передаче значения этих лексем на русский язык переводчики часто используют транскрипцию и транслитерацию (нормкор), калькирование (скромное хвастовство), но чаще всего приходится прибегать к описательному переводу.

\section{$* * *$}

1. Журавлёва Н.Г. Феномен "модного" слова: лингвопрагматический аспект. АКД. - Ставрополь, 2010. $-25 \mathrm{c}$.

2. Кронгауз М.А. Семантика. - М., Российский государственный гуманитарный университет, 2001. 399 c.

3. Молдованова Л.И. Устаревшие слова в языке и публицистическом тексте: структура и особенности функционирования // Филология как средоточие знаний о мире: Сборник научных трудов. МоскваКраснодар: Просвещение-Юг, 2008. С. 81-85.

4. Capoor B. A General Theory of Buzzwords: Synergistic Meta-Linguistic Paradigm Shifts // Inquiries $\begin{array}{lllllll}\text { (journal): } & \text { Linguistics. } 2017, \quad \text { Vol. } 9 & \text { No. } 02 & \text { pg. 2/2. URL: }\end{array}$ http://www.inquiriesjournal.com/articles/1538/2/a-general-theory-of-buzzwords-synergistic-metalinguistic-paradigm-shifts

5. 5. Macmillan Dictionary. Buzzword. [Электронный pecypc] / Macmillan, - 2015. URL: http://www.macmillandictionary.com/

6. Urban dictionary. [Электронный pecypc]. URL: http://ru.urbandictionary.com/

7. Vogue words, buzz words and catch phrases. Языки и перевод. [Электронный ресурc] . URL: http://www.helennic.narod.ru/vogue.htm

\section{Сатцаев Э.Б. \\ Языковая ситуация и языковая политика в регионах ираноязычных народов}

Северо-Осетинский институт гуманитарных и соичильных исследований им. В.И. Абаева - филиал Федерального государственного бюджетного учреждения науки Федерального научного иеентра «Владикавказский научный центр Российской академии наук» (Россия, Владикавказ)

doi: $10.18411 / s p c-26-10-2017-06$

idsp: 000001:spc-26-10-2017-06

Иранские языки распространены в Иране, Афганистане, Таджикистане, на Кавказе (Южная и Северная Осетия), в Ираке, Турции, Пакистане. Численность говорящих на иранских языках людей превышает 140 млн человек.

Историко-генетическая классификация делит иранские языки на две основные группы - западную и восточную с членением каждой из них на северную и южную подгруппы[2].

Наиболее значимыми иранскими языками являются персидский, таджикский, дари, афганский (пушту), курдский, осетинский и белуджский языки.

К иранским языкам относятся и ряд менее значительных по статусу и численности говорящего на них населения языки и диалекты.

Наиболее распространенным и значимым иранским языком является персидский (фарси). Он является официальным языком Исламской республики Иран. В качестве государственного и литературного языка и, являясь языком господствующей нации, он обязателен в качестве языка обучения на всей территории страны[2, 291-294; 4,5-14].

Иран является многонациональным государством, численность населения которого составляет более 80 млн человек. 